Article

\title{
Significance of Velocity Slip in Convective Flow of Carbon Nanotubes
}

\author{
Ali Saleh Alshomrani and Malik Zaka Ullah *D \\ Department of Mathematics, Faculty of Science, King Abdulaziz University, Jeddah 21589, Saudi Arabia; \\ aszalshomrani@kau.edu.sa \\ * Correspondence: malikzakas@gmail.com
}

Received: 7 April 2019; Accepted: 18 April 2019; Published: 17 May 2019

\begin{abstract}
The present article inspects velocity slip impacts in three-dimensional flow of water based carbon nanotubes because of a stretchable rotating disk. Nanoparticles like single and multi walled carbon nanotubes (CNTs) are utilized. Graphical outcomes have been acquired for both single-walled carbon nanotubes (SWCNTs) and multi-walled carbon nanotubes (MWCNTs). The heat transport system is examined in the presence of thermal convective condition. Proper variables lead to a strong nonlinear standard differential framework. The associated nonlinear framework has been tackled by an optimal homotopic strategy. Diagrams have been plotted so as to examine how the temperature and velocities are influenced by different physical variables. The coefficients of skin friction and Nusselt number have been exhibited graphically. Our results indicate that the skin friction coefficient and Nusselt number are enhanced for larger values of nanoparticle volume fraction.
\end{abstract}

Keywords: stretchable rotating disk; CNTs (MWCNTs and SWCNTs); velocity slip; convective boundary condition; OHAM

\section{Introduction}

The investigation of liquid flow by a rotating disk has various applications in aviation science, pivot of hardware, synthetic enterprises and designing, creating frameworks of warm power, rotor-stator frameworks, medicinal contraption, electronic and PC putting away apparatuses, gem developing wonders, machines of air cleaning, nourishment preparing advances, turbo apparatus and numerous others. Von Karman [1] analyzed flow of thick fluid by a rotating disk. Turkyilmazoglu and Senel [2] explored effects of heat and mass transport in thick liquid flow over a permeable rotating disk. Rashidi et al. [3] dissected MHD flow of viscous liquid because of a turn of disk. Turkyilmazoglu [4] exhibited nanoliquid flow by a rotating plate. Hatami et al. [5] examined laminar flow of a thick nanofluid because of the revolution and constriction of disks. Nanoliquid flow because of an extending disk is considered by Mustafa et al. [6]. Sheikholeslami et al. [7] examined nanoliquid flow by a slanted rotatory plate. Recently Hayat et al. [8] analyzed MHD nanoliquid flow over a rotatory disk with slip impacts.

Carbon nanotubes (CNTs) were first discovered by Lijima in 1991. CNTs have long cylindrical pofiles such as frames of carbon atoms with diameter ranges from $0.70-50 \mathrm{~nm}$. CNTs have individual importance in nano-technology, hardwater, air purification systems, structural composite materials, conductive plastics, extra strong fibres, sensors, flat-panel displays, gas storage, biosensors and many others. Thus Choi et al. [9] examined anamolous enhancement of thermal conductivity in nanotubes suspension. Ramasubramaniam et al. [10] examined homogeneous polymer composites/carbon nanotubes for electrical utilizations. Xue [11] proposed a relation for CNT-based composites. Heat transfer enhancement using carbon nanotubes-based-non-Newtonian nanofluids is discussed by Kamali et al. [12]. Wang et al. [13] illustrated laminar flows of nanofluids containing single-walled 
carbon nanotubes (SWCNT) and multi-walled carbon nanotubes (MWCNTs). Hammouch et al. [14] analyzed squeezed flow of CNTs between parallel disks. Thermal transfer upgrade in front aligned contracting channel by taking FMWCNT nanoliquids is analyzed by Safaei et al. [15]. MHD flow of carbon nanotubes is portrayed by Ellahi et ai. [16]. Karimipour et al. [17] dissected MHD laminar flow of carbon nanotubes in a microchannel with a uniform warmth transition. Hayat et al. [18] represented homogeneous-heterogeneous responses in nanofluid flows over a non-direct extending surface of variable thickness. Unsteady squeezed flow of CNTs with convective surface was contemplated by Hayat et al. [19]. Hayat et al. [20] likewise talked about Darcy Forchheimer flow of CNTs over a turning plate. Further relevant investigations on nanofluids can be seen through the studies [21-25].

Motivated by the aforementioned applications of rotating flows, the underlying objective of this article is to develop a mathematical model for three-dimensional flow of water-based carbon nanotubes because of a stretchable rotating disk considering velocity slip effects. Thermal conductivity of carbon nanotubes is estimated through the well-known Xue model. Such research work was not carried out in the past even in the absence of a convective heating surface. Researchers also found that dispersion of carbon nanotubes in water elevates the thermal conductivity of the resulting nanofluid by $100 \%$ (see Choi et al. [9]). Both single-walled carbon nanotubes (SWCNTs) and multi-walled carbon nanotubes (MWCNTs) are considered. Optimal homotopic strategy (OHAM) [26-35] is utilized for solutions of temperature and velocities. Impacts of different flow variables are examined and investigated. Nusselt number and skin friction have been analyzed graphically. Emphasis is given to the role of the main ingredients of the problem, namely volume fraction of carbon nanotubes and a rotating stretchable disk. The benefits of carbon nanotubes towards heat transfer enhancement are also justified via thorough analysis.

\section{Mathematical Formulation}

Let us assume three-dimensional flow of water-based carbon nanotubes by a stretchable rotating disk. The disk at $z=0$ rotates subject to constant angular velocity $\Omega$ (see Figure 1 ). Let us assume CNT nanoparticles: SWCNTs and MWCNTs within base liquid (water). Due to axial symmetry, derivatives of $\varphi$ are neglected. The surface of the disk has temperature $T_{f}$, while ambient fluid temperature is $T_{\infty}$. The velocity components are $(u, v, w)$ in cylindrical coordinate $(r, \varphi, z)$ respectively. The resulting boundary-layer expressions are [8,20]:

$$
\begin{gathered}
\frac{\partial u}{\partial r}+\frac{u}{r}+\frac{\partial w}{\partial z}=0 \\
u \frac{\partial u}{\partial r}-\frac{v^{2}}{r}+w \frac{\partial u}{\partial z}=v_{n f}\left(\frac{\partial^{2} u}{\partial r^{2}}+\frac{\partial^{2} u}{\partial z^{2}}+\frac{1}{r} \frac{\partial u}{\partial r}-\frac{u}{r^{2}}\right), \\
u \frac{\partial v}{\partial r}+\frac{u v}{r}+w \frac{\partial v}{\partial z}=v_{n f}\left(\frac{\partial^{2} v}{\partial r^{2}}+\frac{\partial^{2} v}{\partial z^{2}}+\frac{1}{r} \frac{\partial v}{\partial r}-\frac{v}{r^{2}}\right), \\
u \frac{\partial w}{\partial r}+w \frac{\partial w}{\partial z}=v_{n f}\left(\frac{\partial^{2} w}{\partial r^{2}}+\frac{\partial^{2} w}{\partial z^{2}}+\frac{1}{r} \frac{\partial w}{\partial r}\right), \\
u \frac{\partial T}{\partial r}+w \frac{\partial T}{\partial z}=\alpha_{n f}\left(\frac{\partial^{2} T}{\partial r^{2}}+\frac{\partial^{2} T}{\partial z^{2}}+\frac{1}{r} \frac{\partial T}{\partial r}\right),
\end{gathered}
$$

with subjected boundary conditions [8]:

$$
\begin{gathered}
u=r s+L_{1} \mu_{n f} \frac{\partial u}{\partial z}, v=r \Omega+L_{1} \mu_{n f} \frac{\partial v}{\partial z}, w=0,-k_{n f} \frac{\partial T}{\partial z}=h_{f}\left(T_{f}-T\right) \text { at } z=0, \\
u \rightarrow 0, v \rightarrow 0, T \rightarrow T_{\infty} \text { as } z \rightarrow \infty .
\end{gathered}
$$

Here $u, v$ and $w$ depict flow velocities in increasing directions of $r, \varphi$ and $z$ respectively, while $v_{n f}=\left(\mu_{n f} / \rho_{n f}\right)$ stands for kinematic viscosity, $\alpha_{n f}=k_{n f} /\left(\rho c_{p}\right)_{n f}$ for thermal diffusivity, $\mu_{n f}$ for dynamic viscosity, $L_{1}$ for wall-slip coefficient, $T$ for fluid temperature, $k_{n f}$ for thermal conductivity of 
nanofluids, $\rho_{n f}$ for effective density, $k_{C N T}$ for thermal conductivity of CNTs and $\left(\rho c_{p}\right)_{n f}$ for effective heat capacitance of nanoparticle material. Xue [11] proposed a theoratical model which is expressed by

$$
\begin{aligned}
& \rho_{n f}=\rho_{f}(1-\phi)+\rho_{C N T} \phi, \mu_{n f}=\frac{\mu_{f}}{(1-\phi)^{2.5}}, \\
& \left(\rho c_{p}\right)_{n f}=\left(\rho c_{p}\right)_{f}(1-\phi)+\left(\rho c_{p}\right)_{C N T} \phi, \\
& \frac{k_{n f}}{k_{f}}=\frac{(1-\phi)+2 \phi \frac{k_{C N T}}{k_{C N T}-k_{f}} \ln \frac{{ }^{C} C N T+k_{f}}{2 k_{f}}}{(1-\phi)+2 \phi \frac{k_{f}}{k_{C N T}-k_{f}} \ln \frac{k_{C N T}+k_{f}}{2 k_{f}}},
\end{aligned}
$$

where $\phi$ represents solid volume fraction of nanoparticles and $n f$ represents thermophysical properties of nanofluid. Table 1 describes thermo-physical features of water and CNT.

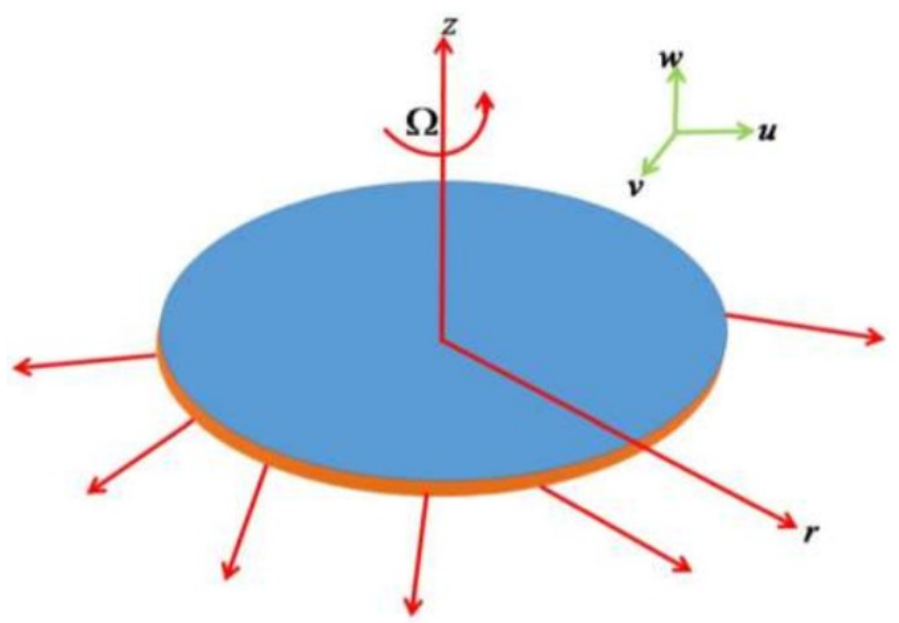

Figure 1. Geometry of the problem.

Table 1. Thermophysical features of water and carbon nanotubes (CNT).

\begin{tabular}{cccc}
\hline Physical Features & Water & CNT & \\
\hline & & SWCNTs & MWCNTs \\
\hline$\rho\left(\mathrm{kg} / \mathrm{m}^{3}\right)$ & 997.1 & 2600 & 1600 \\
$k(\mathrm{~W} / \mathrm{mK})$ & 0.613 & 6600 & 3000 \\
$c_{p}(\mathrm{~J} / \mathrm{kgK})$ & 4179 & 425 & 796 \\
\hline
\end{tabular}

We now introduce the following transformations:

$$
\begin{gathered}
u=r \Omega f^{\prime}(\zeta), v=r \Omega g(\zeta), w=-\sqrt{2 v_{f} \Omega} f(\zeta), \\
\zeta=z\left(\frac{2 \Omega}{v_{f}}\right)^{1 / 2}, \theta(\zeta)=\frac{T-T_{\infty}}{T_{f}-T_{\infty}} .
\end{gathered}
$$

Expression (1) is automatically satisfied while Equations (2)-(8) yield

$$
\begin{gathered}
\frac{1}{(1-\phi)^{5 / 2}\left(1-\phi+\frac{\rho_{C N T}}{\rho_{f}} \phi\right)} f^{\prime \prime \prime}(\zeta)+f(\zeta) f^{\prime \prime}(\zeta)-\frac{1}{2} f^{\prime 2}(\zeta)+\frac{1}{2} g^{2}(\zeta)=0, \\
\frac{1}{(1-\phi)^{5 / 2}\left(1-\phi+\frac{\rho_{C N T}}{\rho_{f}} \phi\right)} g^{\prime \prime}(\zeta)+f(\zeta) g^{\prime}(\zeta)-f^{\prime}(\zeta) g(\zeta)=0, \\
\frac{1}{\operatorname{Pr}} \frac{k_{n f}}{k_{f}} \theta^{\prime \prime}(\zeta)+\left(1-\phi+\phi \frac{\left(\rho c_{p}\right)_{C N T}}{\left(\rho c_{p}\right)_{f}}\right) f(\zeta) \theta^{\prime}(\zeta)=0
\end{gathered}
$$


with the boundary conditions

$$
\begin{gathered}
f(0)=0, f^{\prime}(0)=C+\frac{\alpha}{(1-\phi)^{5 / 2}} f^{\prime \prime}(0), g(0)=1+\frac{\alpha}{(1-\phi)^{5 / 2}} g^{\prime}(0), \theta^{\prime}(0)=-\frac{k_{f}}{k_{n f}} B i(1-\theta(0)), \\
f^{\prime}(\infty) \rightarrow 0, g(\infty) \rightarrow 0, \theta(\infty) \rightarrow 0 .
\end{gathered}
$$

Here $C$ stands for stretching-strength parameter, $\alpha$ for velocity slip number, Pr for Prandtl number and $B i$ for the Biot number. These numbers are described by:

$$
C=\frac{s}{\Omega}, \alpha=L_{1} \mu_{f}\left(\frac{2 \Omega}{v_{f}}\right)^{1 / 2}, B i=\frac{h_{f}}{k_{f}}\left(\frac{v_{f}}{2 \Omega}\right)^{1 / 2}, \operatorname{Pr}=\frac{v_{f}\left(\rho c_{p}\right)_{f}}{k_{f}} .
$$

Nusselt number and skin friction are defined by

$$
\left.\begin{array}{c}
\operatorname{Re}_{r}^{-1 / 2} N u_{r}=-\frac{k_{n f}}{k_{f}} \theta^{\prime}(0), \\
\operatorname{Re}_{r}^{1 / 2} C_{f}=\frac{1}{(1-\phi)^{5 / 2}}\left(f^{\prime \prime}(0)^{2}+g^{\prime}(0)^{2}\right)^{1 / 2},
\end{array}\right\}
$$

where $\operatorname{Re}_{r}=2 \Omega r^{2} / v_{f}$ depicts the local Reynolds number.

\section{Solutions by OHAM}

The optimal solutions of expressions (10)-(12) through (13) and (14) have been established by considering optimal homotopic strategy (OHAM). The proper operators and guesses are

$$
\begin{gathered}
f_{0}(\zeta)=\frac{C}{\left(1+\frac{\alpha}{(1-\phi)^{5 / 2}}\right)}\left(1-e^{-\zeta}\right), g_{0}(\zeta)=\frac{1}{\left(1+\frac{\alpha}{(1-\phi)^{5 / 2}}\right)} e^{-\zeta}, \theta_{0}(\zeta)=\frac{B i}{\left(\frac{k_{n f}}{k_{f}}+B i\right)} e^{-\zeta}, \\
\mathcal{L}_{g}=\frac{d^{2} g}{d \zeta^{2}}-g, \mathcal{L}_{\theta}=\frac{d^{2} \theta}{d \zeta^{2}}-\theta, \mathcal{L}_{f}=\frac{d^{3} f}{d \zeta^{3}}-\frac{d f}{d \zeta} .
\end{gathered}
$$

The above operators satisfy

$$
\mathcal{L}_{f}\left[F_{1}^{* * * *}+F_{2}^{* * * *} e^{\zeta}+F_{3}^{* * * *} e^{-\zeta}\right]=0, \mathcal{L}_{g}\left[F_{4}^{* * * *} e^{\zeta}+F_{5}^{* * * *} e^{-\zeta}\right]=0, \mathcal{L}_{\theta}\left[F_{6}^{* * * *} e^{\zeta}+F_{7}^{* * * *} e^{-\zeta}\right]=0,
$$

in which $F_{i}^{* * * *}(i=1-7)$ portrays arbitrary constants. The $m$-th and zero-th order systems are easily established in view of above operators. By using BVPh2.0 of the software Mathematica, the obtained deformation problems have been computed.

\section{Optimal Convergence-Control Parameters}

In homotopic solutions, the non zero auxiliary variables $\hbar_{f}, h_{g}$ and $\hbar_{\theta}$ determine the convergence portion and also rate of homotopy solution. The idea of minimization has been applied by defining averaged squared residuals errors as proposed by Liao [26].

$$
\begin{gathered}
\varepsilon_{m}^{f}=\frac{1}{k+1}_{j=0}^{k}\left[\mathcal{N}_{f}\left(\prod_{i=0}^{m} \hat{f}(\zeta),{ }_{i=0}^{m} \hat{g}(\zeta)\right)_{\zeta=j \delta \zeta}\right]^{2}, \\
\varepsilon_{m}^{g}=\frac{1}{k+1}_{j=0}^{k}\left[\mathcal{N}_{g}\left({ }_{i=0}^{m} \hat{f}(\zeta),{ }_{i=0}^{m} \hat{g}(\zeta)\right)_{\zeta=j \delta \zeta}\right]^{2}, \\
\varepsilon_{m}^{\theta}=\frac{1}{k+1}_{j=0}^{k}\left[\mathcal{N}_{\theta}\left({ }_{i=0}^{m} \hat{f}(\zeta),{ }_{i=0}^{m} \hat{g}(\zeta),{ }_{i=0}^{m} \hat{\theta}(\zeta)\right)_{\zeta=j \delta \zeta}\right]^{2} .
\end{gathered}
$$


Following Liao [26]:

$$
\varepsilon_{m}^{t}=\varepsilon_{m}^{f}+\varepsilon_{m}^{g}+\varepsilon_{m}^{\theta}
$$

where $\varepsilon_{m}^{t}$ represents total squared residual error, $\delta \zeta=0.5$ and $k=20$. At the second order of deformations, convergence-control parameters for SWCNTs-water have optimal values i.e., $h_{f}=-0.35923, h_{g}=-0.736096$ and $h_{\theta}=-0.00105197$ and total averaged squared residuals error is $\varepsilon_{m}^{t}=-0.0255367$ while optimal data of convergence-control parameters for MWCNTs-water is $h_{f}=-0.385385, h_{g}=-0.729057$ and $h_{\theta}=-0.00232643$ and total averaged squared residuals error is $\varepsilon_{m}^{t}=-0.025173$. Figures 2 and 3 display error plots for MWCNTs-water and SWCNTs-water. Tables 2 and 3 show that averaged squared residuals error decreases for higher order deformations.

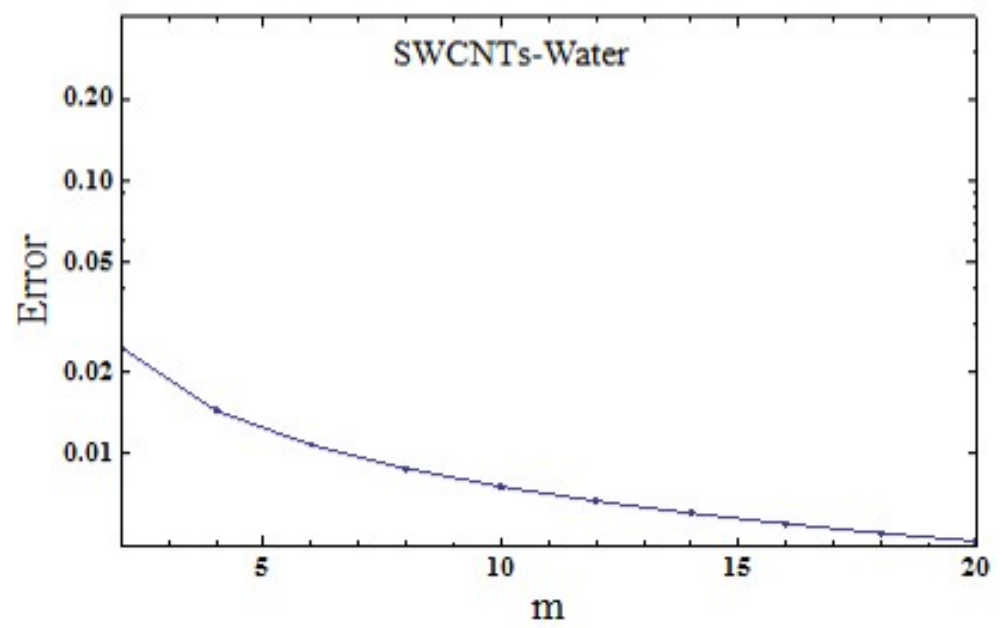

Figure 2. Error sketch for SWCNTs-Water.

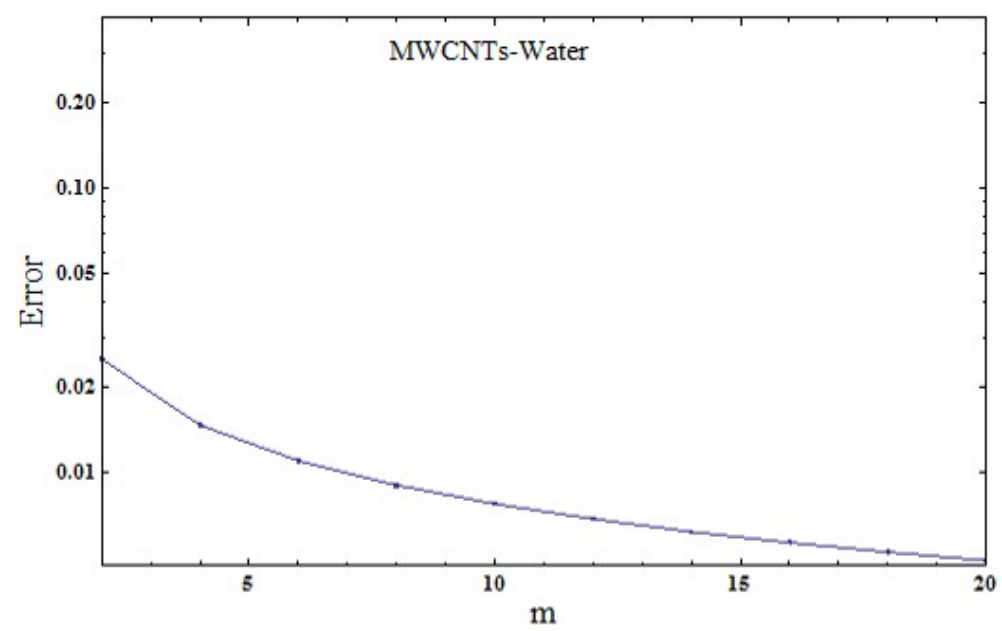

Figure 3. Error sketch for MWCNTs-Water.

Table 2. Individual averaged squared residuals errors for single-walled carbon nanotubes (SWCNTs)-water.

\begin{tabular}{cccc}
\hline$m$ & $\varepsilon_{m}^{f}$ & $\varepsilon_{m}^{g}$ & $\varepsilon_{m}^{\theta}$ \\
\hline 2 & $9.95225 \times 10^{-5}$ & $2.35341 \times 10^{-2}$ & $7.29447 \times 10^{-7}$ \\
6 & $4.17686 \times 10^{-5}$ & $1.03083 \times 10^{-2}$ & $6.04738 \times 10^{-7}$ \\
10 & $2.95796 \times 10^{-5}$ & $7.24672 \times 10^{-3}$ & $5.69806 \times 10^{-7}$ \\
14 & $2.37325 \times 10^{-5}$ & $5.77429 \times 10^{-3}$ & $5.53122 \times 10^{-7}$ \\
18 & $2.01939 \times 10^{-5}$ & $4.88653 \times 10^{-3}$ & $5.43213 \times 10^{-7}$ \\
20 & $1.88867 \times 10^{-5}$ & $4.55942 \times 10^{-3}$ & $5.39608 \times 10^{-7}$ \\
\hline
\end{tabular}


Table 3. Individual averaged squared residuals errors for single-walled carbon nanotubes (MWCNTs)-water.

\begin{tabular}{cccc}
\hline$m$ & $\varepsilon_{m}^{f}$ & $\varepsilon_{m}^{g}$ & $\varepsilon_{m}^{\theta}$ \\
\hline 2 & $1.0164 \times 10^{-4}$ & $2.40503 \times 10^{-2}$ & $7.29447 \times 10^{-7}$ \\
6 & $4.27165 \times 10^{-5}$ & $1.05447 \times 10^{-2}$ & $6.04522 \times 10^{-7}$ \\
10 & $3.02678 \times 10^{-5}$ & $7.41739 \times 10^{-3}$ & $5.69547 \times 10^{-7}$ \\
14 & $2.42942 \times 10^{-5}$ & $5.91293 \times 10^{-3}$ & $5.52829 \times 10^{-7}$ \\
18 & $2.06785 \times 10^{-5}$ & $5.00567 \times 10^{-3}$ & $5.42892 \times 10^{-7}$ \\
20 & $1.93426 \times 10^{-5}$ & $4.67132 \times 10^{-3}$ & $5.39275 \times 10^{-7}$ \\
\hline
\end{tabular}

\section{Results and Discussion}

The present section presents behaviors of various physical parameters like stretching-strength parameter $C$, volume fraction $\phi$, velocity slip parameter $\alpha$ and Biot number Bi on radial $f^{\prime}(\zeta)$ and azimuthal $g(\zeta)$ velocities and temperature $\theta(\zeta)$. The results are obtained for both SWCNTs and MWCNTs. Figure 4 shows variation in the radial velocity $f^{\prime}(\zeta)$ for larger values of $\alpha$. Radial velocity $f^{\prime}(\zeta)$ shows reduction for increasing values of $\alpha$. Figure 5 presents impact of stretching-strength parameter $C$ on radial velocity $f^{\prime}(\zeta)$. For larger values of $C$, the radial velocity shows an increasing trend. Figure 6 depicts the effect of nanoparticle volume fraction $\phi$ on radial velocity $f^{\prime}(\zeta)$. For higher $\phi$, the radial velocity $f^{\prime}(\zeta)$ is increased. Figure 7 presents that how velocity slip parameter $\alpha$ affects the azimuthal velocity $g(\zeta)$. It is observed that an increment in velocity slip parameter $\alpha$ lead to lower $g(\zeta)$. Figure 8 depicts impact of $C$ on azimuthal velocity $g(\zeta)$. Azimuthal velocity reduces for larger values of streching-strength parameter. Figure 9 depicts the impact of nanoparticles volume fraction $\phi$ on $g(\zeta)$. The azimuthal velocity $g(\zeta)$ is increased for higher estimations of $\phi$. Figure 10 examines that how Biot number $B i$ affects the temperature profile. For higher values of $B i$, the temperature field $\theta(\zeta)$ is enhanced. Higher estimations of Biot number correspond to stronger convection which produces higher temperature field and more associated layer thickness. Figure 11 highlights the impact of stretching-strength parameter $C$ on temperature field $\theta(\zeta)$. Temperature field $\theta(\zeta)$ is reduced for increasing values of $C$. Figure 12 presents that how volume fraction $\phi$ affects the temperature field $\theta(\zeta)$. Higher values of $\phi$ shows an enhancement in temperature $\theta(\zeta)$. Figure 13 shows the effects of volume fraction $\phi$ and velocity slip parameter $\alpha$ on $\operatorname{Re}_{r}^{1 / 2} C_{f}$. Skin friction $\operatorname{Re}_{r}^{1 / 2} C_{f}$ is increased for higher estimations of $\phi$. Figure 14 displays the behavior of the volume fraction $\phi$ and Biot number $B i$ on Nusselt number $\operatorname{Re}_{r}^{-1 / 2} N u_{r}$. The Nusselt number is enhanced for increasing values of $\phi$.

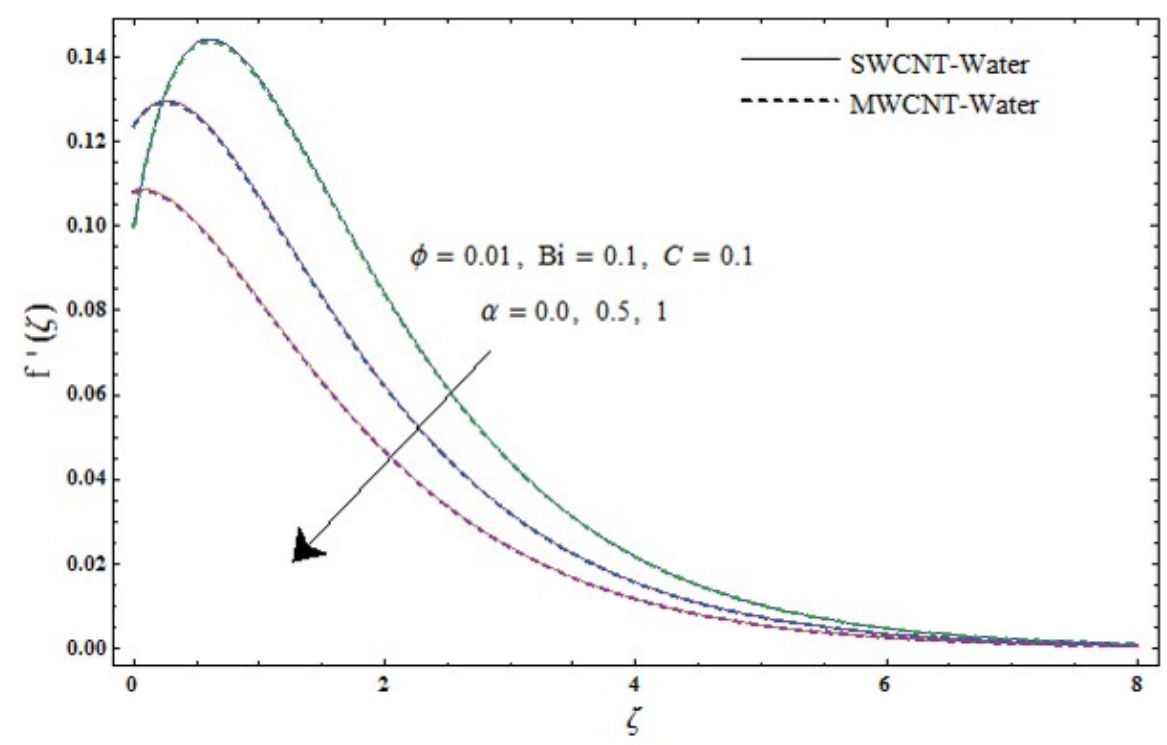

Figure 4. Sketch of $f^{\prime}(\zeta)$ for $\alpha$. 


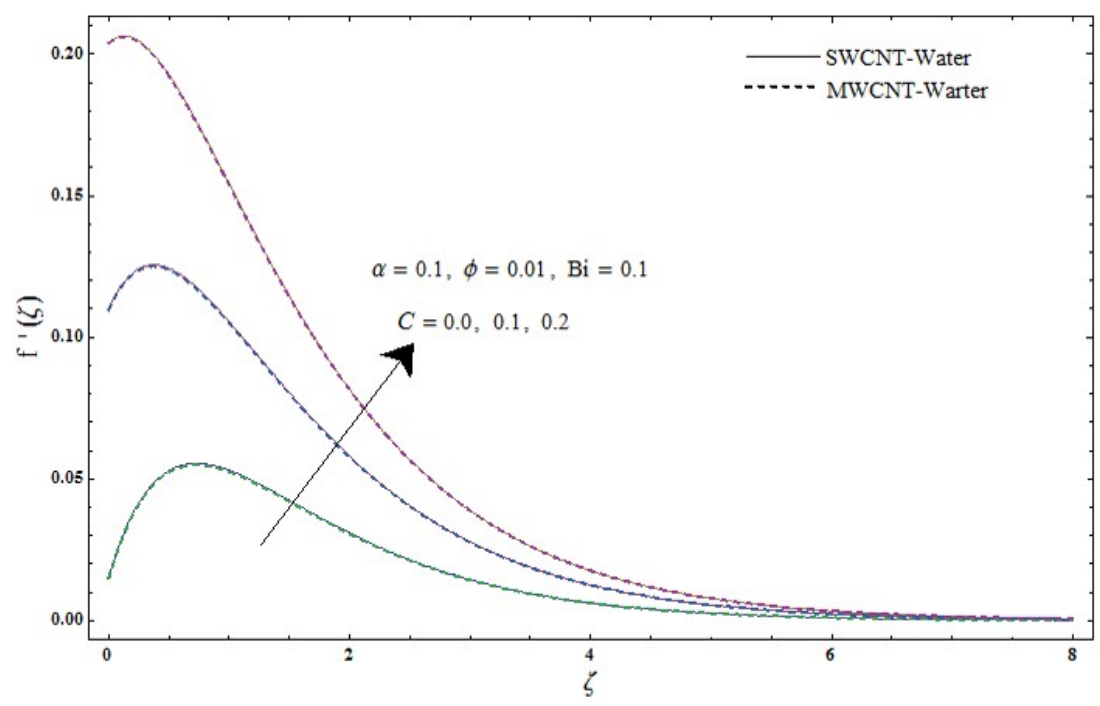

Figure 5. Sketch of $f^{\prime}(\zeta)$ for $C$.

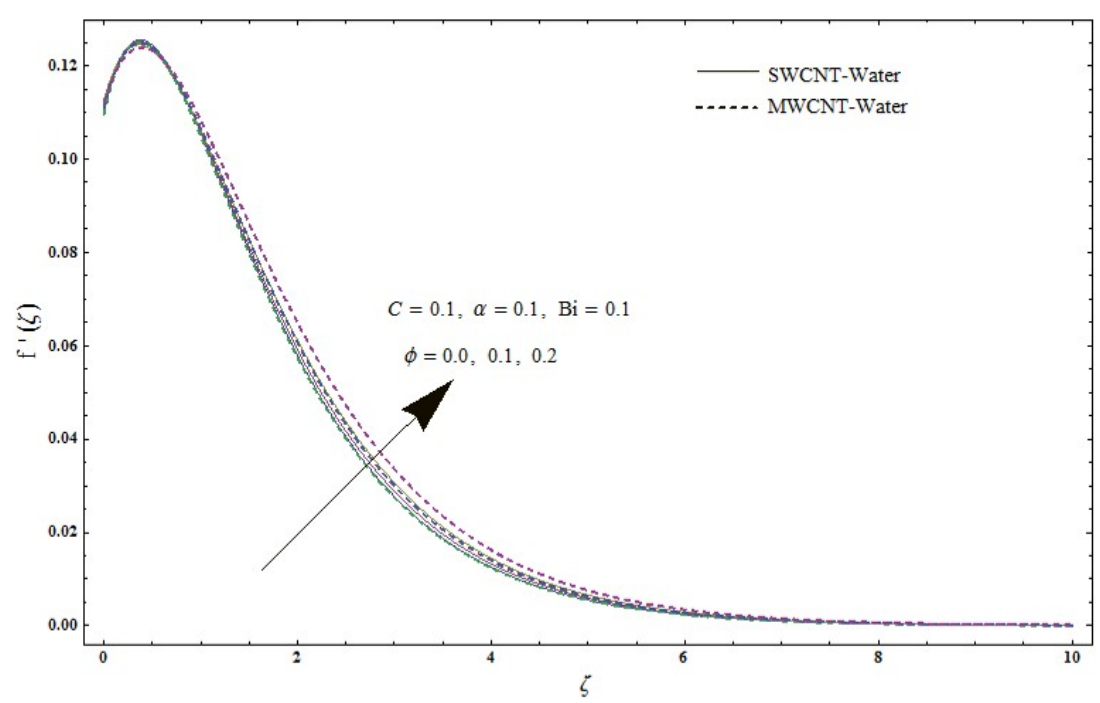

Figure 6. Sketch of $f^{\prime}(\zeta)$ for $\phi$.

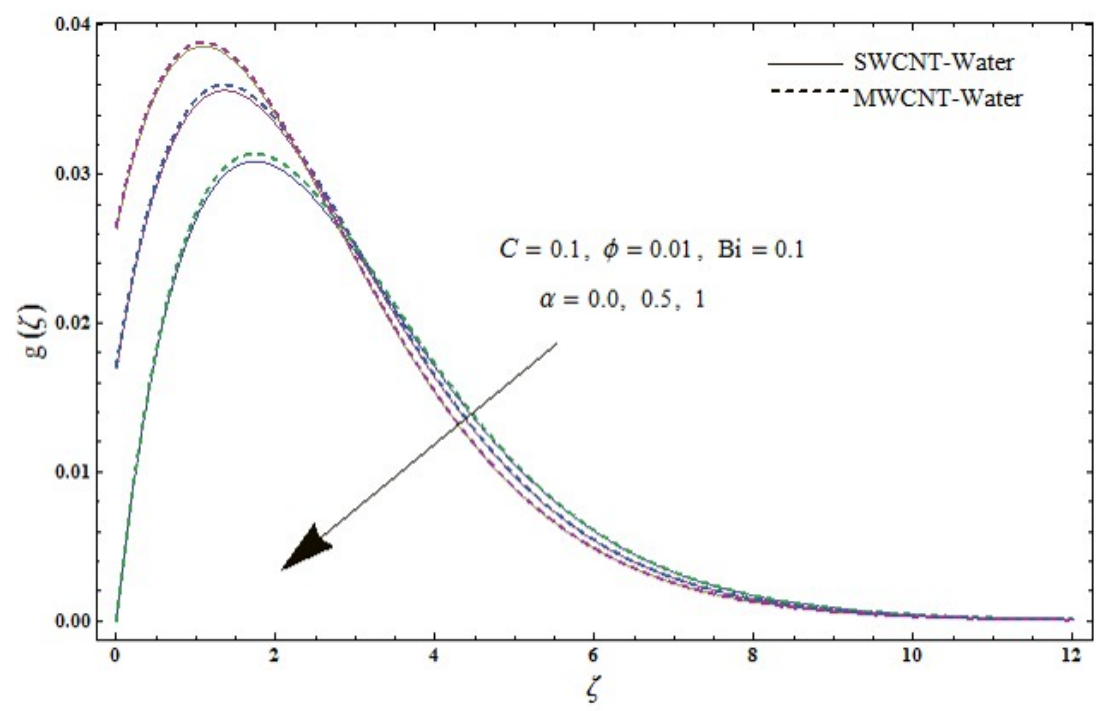

Figure 7. Sketch of $g(\zeta)$ for $\alpha$. 


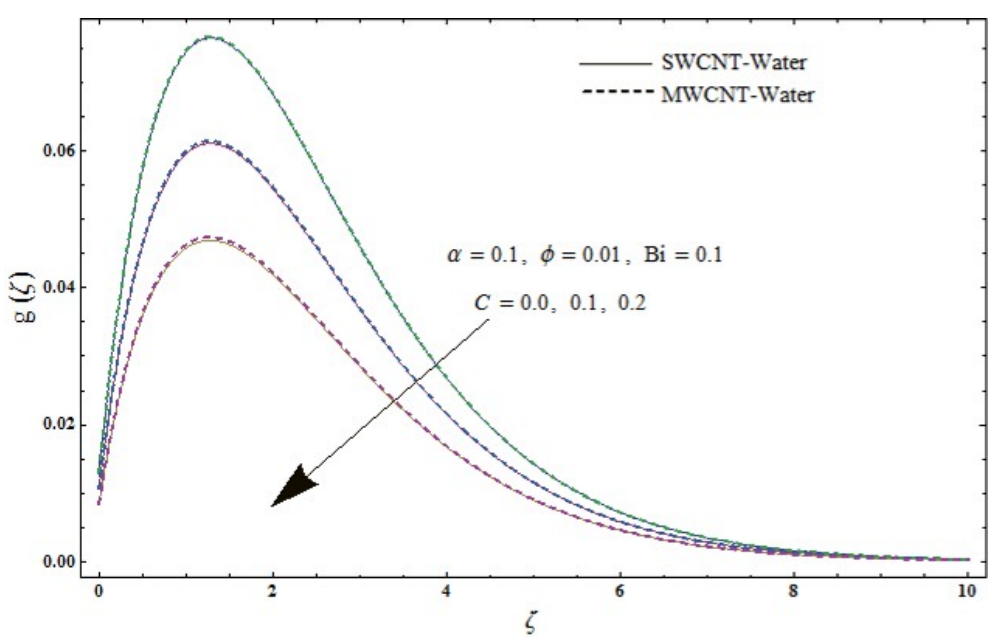

Figure 8. Sketch of $g(\zeta)$ for $C$.

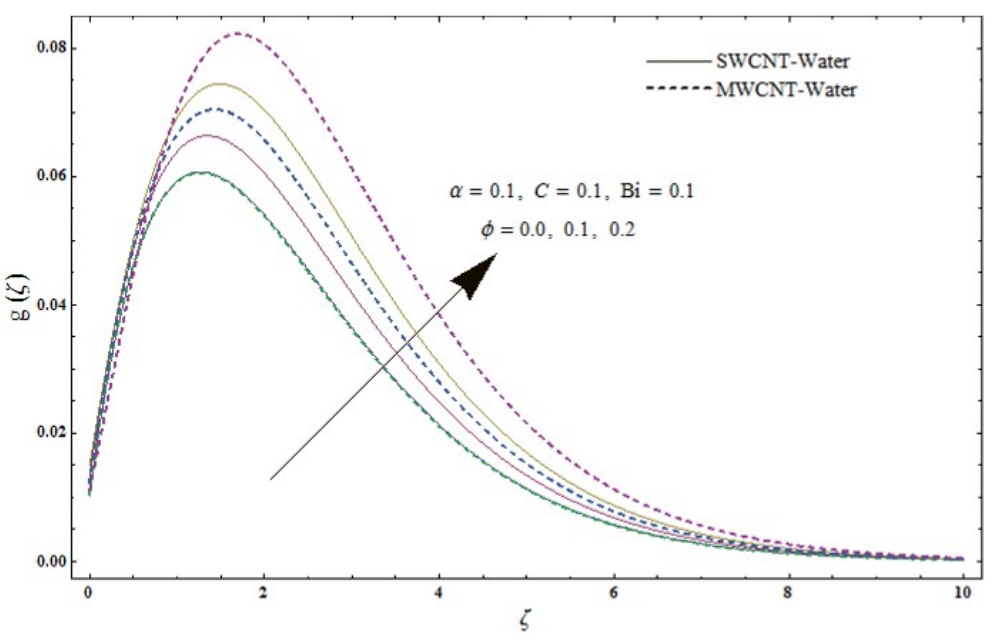

Figure 9. Sketch of $g(\zeta)$ for $\phi$.

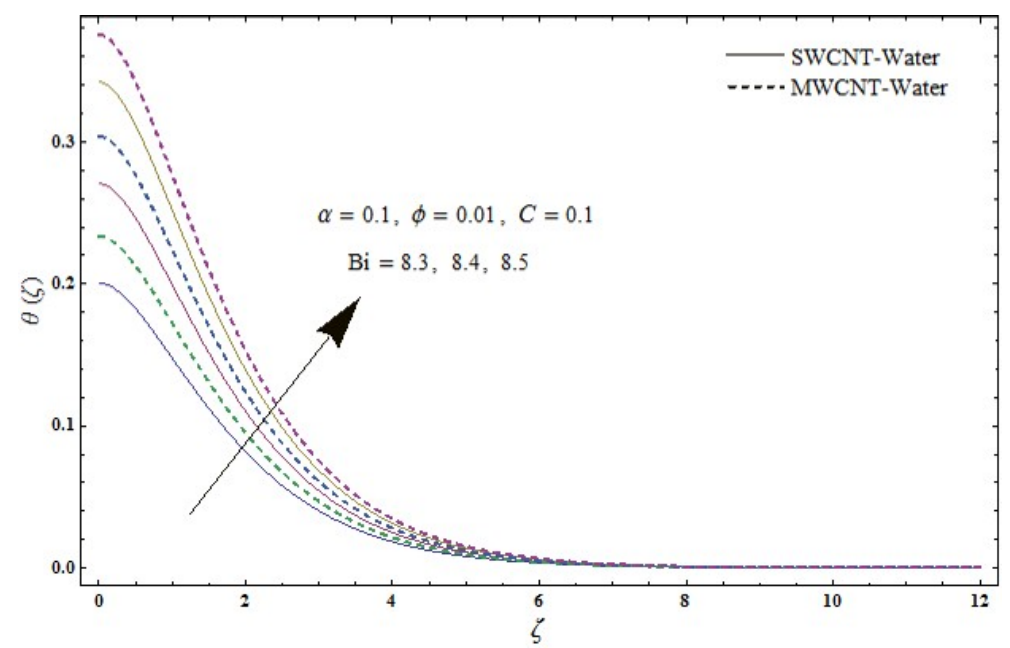

Figure 10. Sketch of $\theta(\zeta)$ for $B i$. 


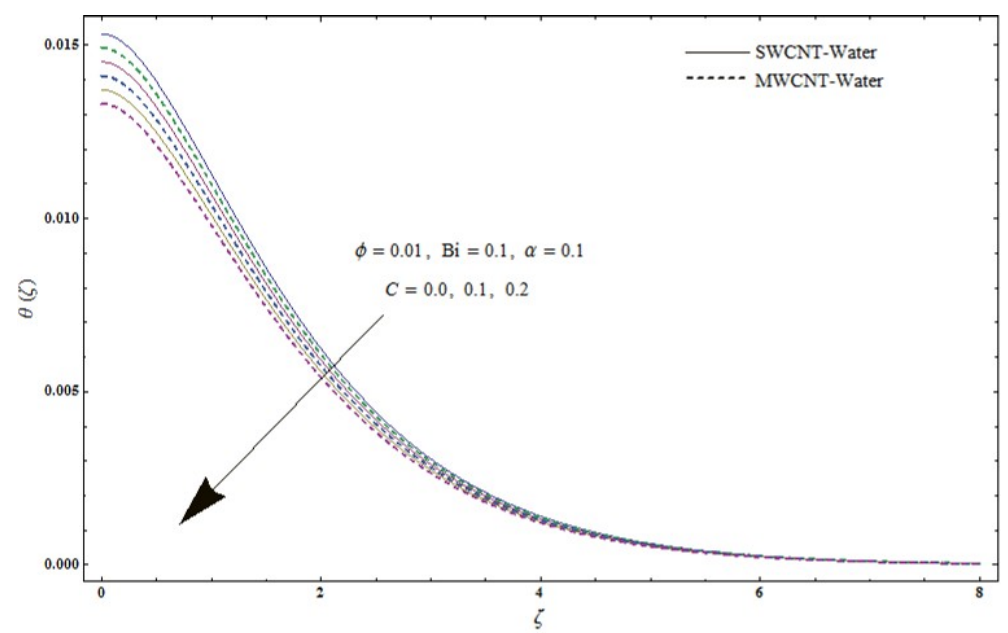

Figure 11. Sketch of $\theta(\zeta)$ for $C$.

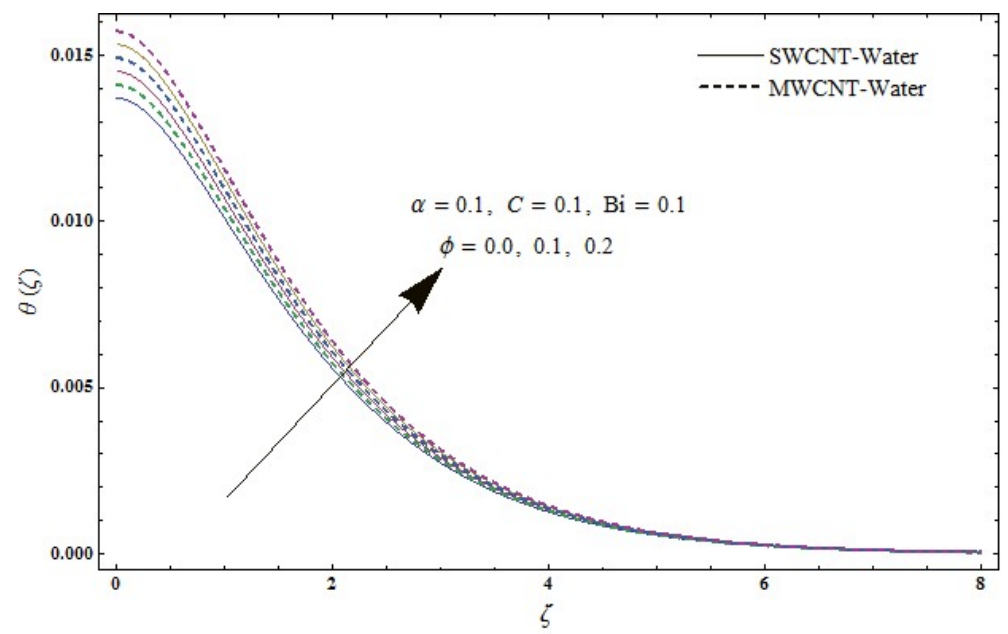

Figure 12. Sketch of $\theta(\zeta)$ for $\phi$.

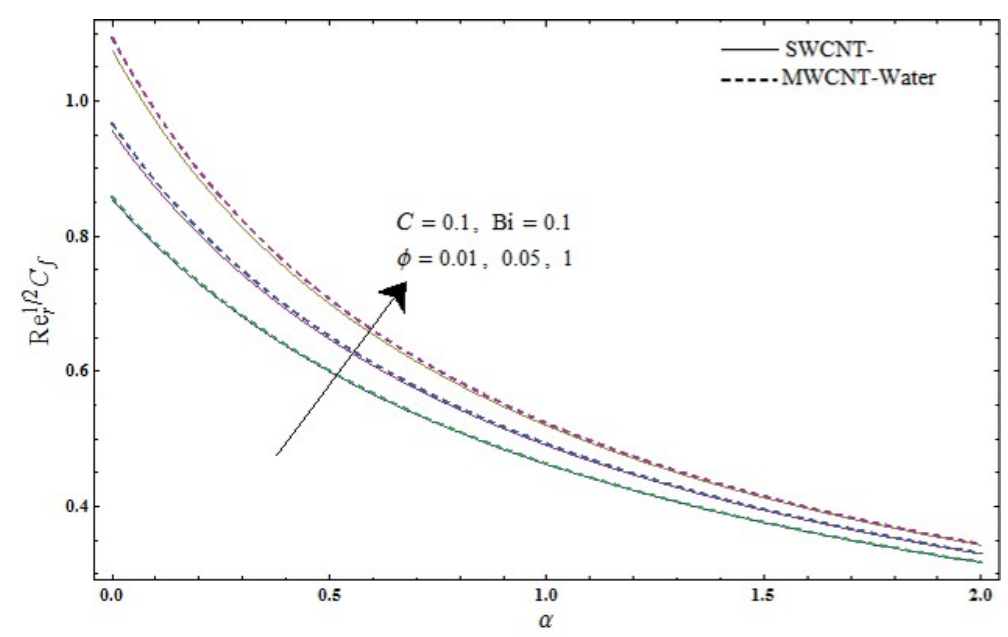

Figure 13. Sketch of $\operatorname{Re}_{r}^{1 / 2} C_{f}$ for $\phi$ and $\alpha$. 


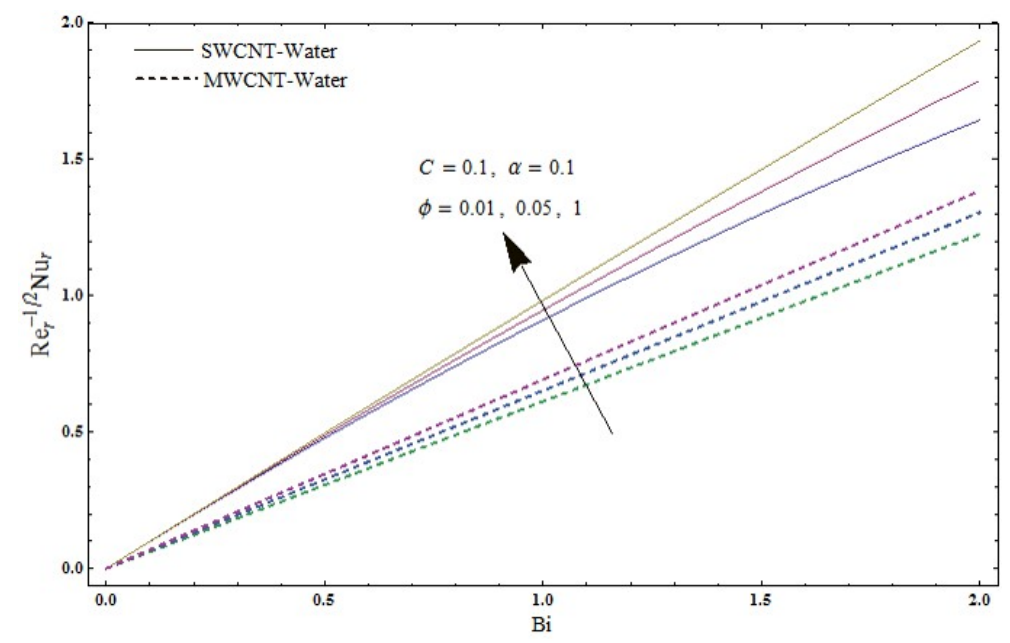

Figure 14. Sketch of $\operatorname{Re}_{r}^{-1 / 2} N u_{r}$ for $\phi$ and $B i$.

\section{Conclusions}

Three-dimensional flow of carbon nanotubes by a stretchable rotating disk with velocity slip effects is studied. Heat transport is explained by convective heating surface. The key findings of current research are listed below:

- Both velocities $f^{\prime}(\zeta)$ and $g(\zeta)$ show reduction for higher values of velocity slip parameter $\alpha$.

- Larger stretching-strength parameter $C$ presents an increase in radial velocity $f^{\prime}(\zeta)$ while opposite trend is noticed for azimuthal velocity $g(\zeta)$ and temperature $\theta(\zeta)$.

- For higher estimations of the volume fraction $\phi$, both the velocity and temperatue field are enhanced.

- $\quad$ Temperature field $\theta(\zeta)$ is enhanced for larger values of the Biot number Bi.

- Nusselt number $\operatorname{Re}_{r}^{-1 / 2} N u_{r}$ is increased for larger values of volume fraction $\phi$.

- Coefficient of skin-friction $\operatorname{Re}_{r}^{1 / 2} C_{f}$ increases for higher volume fraction $\phi$ and velocity slip parameter $\alpha$.

- The used technique for the solution's development has advantages over the other in the sense of the following points:

a. It is independent of small/large physical parameters.

b. It provides a simple way to ensure the convergence of series solutions.

c. It provides a large freedom to choose the base functions and related auxiliary linear operators.

Author Contributions: All the authors contributed equally to the conception of the idea, implementing and analyzing the experimental results, and writing the manuscript.

Funding: This project was funded by the Deanship of Scientific Research (DSR) at King Abdulaziz University, Jeddah, under grant No. G-316-130-38. The authors, therefore, acknowledge with thanks DSR for technical and financial support.

Conflicts of Interest: The authors declare no conflict of interest. 


\section{Nomenclature}

\begin{tabular}{|c|c|c|c|}
\hline$r, \varphi, z$ & space coordinates $[\mathrm{m}]$ & $u, v, w$ & velocity components $\left[\mathrm{m} \cdot \mathrm{s}^{-1}\right]$ \\
\hline$\rho_{f}$ & fluid density $\left[\mathrm{kg} \cdot \mathrm{m}^{-3}\right]$ & $\mu_{f}$ & fluid dynamic viscosity [Pa.s] \\
\hline$k_{n f}$ & $\begin{array}{l}\text { nanofluids themal } \\
\text { conductivity }\left[\mathrm{W} \cdot \mathrm{m}^{-1} \cdot \mathrm{K}^{-1}\right]\end{array}$ & $v_{n f}$ & $\begin{array}{l}\text { kinematic nanofluid } \\
\text { viscosity }\left[\mathrm{m}^{2} \cdot \mathrm{s}^{-1}\right]\end{array}$ \\
\hline$k_{f}$ & $\begin{array}{l}\text { basefluid themal } \\
\text { conductivity }\left[\mathrm{W} \cdot \mathrm{m}^{-1} \cdot \mathrm{K}^{-1}\right]\end{array}$ & $v_{f}$ & $\begin{array}{l}\text { kinematic fluid } \\
\text { viscosity }\left[\mathrm{m}^{2} \cdot \mathrm{s}^{-1}\right]\end{array}$ \\
\hline$\alpha_{f}$ & $\begin{array}{l}\text { thermal diffusivity } \\
\text { of base fluid }\left[\mathrm{m}^{2} \cdot \mathrm{s}^{-1}\right]\end{array}$ & $\alpha_{n f}$ & $\begin{array}{l}\text { thermal diffusivity } \\
\text { of nanofluid }\left[\mathrm{m}^{2} \cdot \mathrm{s}^{-1}\right]\end{array}$ \\
\hline$T_{f}$ & hot fluid temperature $[\mathrm{K}]$ & $T_{\infty}$ & ambient temperature $[\mathrm{K}]$ \\
\hline C & stretching-strength parameter & $k_{C N T}$ & CNTs thermal conductivity $\left[\mathrm{W} \cdot \mathrm{m}^{-1} \cdot \mathrm{K}^{-1}\right]$ \\
\hline$\alpha$ & velocity slip parameter & $\phi$ & nanomaterial volume fraction \\
\hline$B i$ & Biot number & $\operatorname{Pr}$ & Prandtl number \\
\hline$f^{\prime}$ & dimensionless velocity & $N u_{r}$ & Nusselt number \\
\hline$C_{f}$ & skin friction coefficient & $\zeta$ & dimensionless variable \\
\hline $\operatorname{Re}_{r}$ & local Reynolds number & $\theta$ & dimensionless temperature \\
\hline CNTs & carbon nanotubes & $F_{i}^{* * * *}$ & arbitrary constants \\
\hline
\end{tabular}

\section{References}

1. Von Karman, T. Uber laminare and turbulente Reibung. ZAMM Z. Angew. Math. Mech. 1921, 1, $233-252$. [CrossRef]

2. Turkyilmazoglu, M.; Senel, P. Heat and mass transfer of the flow due to a rotating rough and porous disk. Int. J. Therm. Sci. 2013, 63, 146-158. [CrossRef]

3. Rashidi, M.M.; Kavyani, N.; Abelman, S. Investigation of entropy generation in MHD and slip flow over rotating porous disk with variable properties. Int. J. Heat Mass Transf. 2014, 70, 892-917. [CrossRef]

4. Turkyilmazoglu, M. Nanofluid flow and heat transfer due to a rotating disk. Comput. Fluids 2014, 94, 139-146. [CrossRef]

5. Hatami, M.; Sheikholeslami, M.; Gangi, D.D. Laminar flow and heat transfer of nanofluids between contracting and rotating disks by least square method. Power Technol. 2014, 253, 769-779. [CrossRef]

6. Mustafa, M.; Khan, J.A.; Hayat, T.; Alsaedi, A. On Bödewadt flow and heat transfer of nanofluids over a stretching stationary disk. J. Mol. Liq. 2015, 211, 119-125. [CrossRef]

7. Sheikholeslami, M.; Hatami, M.; Ganji, D.D. Numerical investigation of nanofluid spraying on an inclined rotating disk for cooling process. J. Mol. Liq. 2015, 211, 577-583. [CrossRef]

8. Hayat, T.; Muhammad, T.; Shehzad, S.A.; Alsaedi, A. On magnetohydrodynamic flow of nanofluid due to a rotating disk with slip effect: A numerical study. Comput. Methods Appl. Mech. Eng. 2017, 315, 467-477. [CrossRef]

9. Choi, S.U.S.; Zhang, Z.G.; Yu, W.; Lockwood, F.E.; Grulke, E.A. Anomalous thermal conductivity enhancement in nanotube suspensions. Appl. Phys. Lett. 2001, 79, 2252. [CrossRef]

10. Ramasubramaniam, R.; Chen, J.; Liu, H. Homogeneous carbon nanotube/polymer composites for electrical applications. Appl. Phys. Lett. 2003, 83, 2928. [CrossRef]

11. Xue, Q.Z. Model for thermal conductivity of carbon nanotube-based composites. Phys. B Condens. Matter 2005, 368, 302-307. [CrossRef]

12. Kamali, R.; Binesh, A. Numerical investigation of heat transfer enhancement using carbon nanotube-based non-Newtonian nanofluids. Int. Commun. Heat Mass Transf. 2010, 37, 1153-1157. [CrossRef]

13. Wang, J.; Zhu, J.; Zhang, X.; Chen, Y. Heat transfer and pressure drop of nanofluids containing carbon nanotubes in laminar flows. Exp. Therm. Fluid Sci. 2013, 44, 716-721. [CrossRef]

14. Haq, R.U.; Hammouch, Z.; Khan, W.A. Water-based squeezing flow in the presence of carbon nanotubes between two parallel disks. Therm. Sci. 2014, 20, 148. [CrossRef] 
15. Safaei, M.R.; Togun, H.; Vafai, K.; Kazi, S.N.; Badarudin, A. Investigation of heat transfer enhancement in a forward-facing contracting channel using FMWCNT nanofluids. Numer. Heat Transf. Part A 2014, 66, 1321-1340. [CrossRef]

16. Ellahi, R.; Hassan, M.; Zeeshan, A. Study of natural convection MHD nanofluid by means of single and multi walled carbon nanotubes suspended in a salt water solutions. IEEE Trans. Nanotechnol. 2015, 14, 726-734. [CrossRef]

17. Karimipour, A.; Taghipour, A.; Malvandi, A. Developing the laminar MHD forced convection flow of water/FMWNT carbon nanotubes in a microchannel imposed the uniform heat flux. J. Magn. Magn. Mater. 2016, 419, 420-428. [CrossRef]

18. Hayat, T.; Hussain, Z.; Muhammad, T.; Alsaedi, A. Effects of homogeneous and heterogeneous reactions in flow of nanofluids over a nonlinear stretching surface with variable surface thickness. J. Mol. Liq. 2016, 221, 1121-1127. [CrossRef]

19. Hayat, T.; Muhammad, K.; Farooq, M.; Alsaedi, A. Unsteady squeezing flow of carbon nanotubes with convective boundary conditions. PLoS ONE 2016, 11, e0152923. [CrossRef]

20. Hayat, T.; Haider, F.; Muhammad, T.; Alsaedi, A. On Darcy-Forchheimer flow of carbon nanotubes due to a rotating disk. Int. J. Heat Mass Transf. 2017, 112, 248-254. [CrossRef]

21. Akbar, N.S.; Khan, Z.H.; Nadeem, S. The combined effects of slip and convective boundary conditions on stagnation-point flow of CNT suspended nanofluid over a stretching sheet. J. Mol. Liq. 2014, 196, 21-25. [CrossRef]

22. Arani, A.A.A.; Akbari, O.A.; Safaei, M.R.; Marzban, A.; Alrashed, A.A.A.A.; Ahmadi, G.R.; Nguyen, T.K. Heat transfer improvement of water/single-wall carbon nanotubes (SWCNT) nanofluid in a novel design of a truncated double-layered microchannel heat sink. Int. J. Heat Mass Transf. 2017, 113, 780-795. [CrossRef]

23. Goodarzi, M.; Javid, S.; Sajadifar, A.; Nojoomizadeh, M.; Motaharipour, S.H.; Bach, Q.V.; Karimipour, A. Slip velocity and temperature jump of a non-Newtonian nanofluid, aqueous solution of carboxy-methyl cellulose/aluminum oxide nanoparticles, through a microtube. Int. J. Numer. Methods Heat Fluid Flow 2018. [CrossRef]

24. Ellahi, R.; Zeeshan, A.; Hussain, F.; Asadollahi, A. Peristaltic blood flow of couple stress fluid suspended with nanoparticles under the influence of chemical reaction and activation energy. Symmetry 2019, 11, 276. [CrossRef]

25. Suleman, M.; Ramzan, M.; Ahmad, S.; Lu, D.; Muhammad, T.; Chung, J.D. A numerical simulation of silver-water nanofluid flow with impacts of Newtonian heating and homogeneous-heterogeneous reactions past a nonlinear stretched cylinder. Symmetry 2019, 11, 295. [CrossRef]

26. Liao, S.J. An optimal homotopy-analysis approach for strongly nonlinear differential equations. Commun. Nonlinear. Sci. Numer. Simul. 2010, 15, 2003-2016. [CrossRef]

27. Dehghan, M.; Manafian, J.; Saadatmandi, A. Solving nonlinear fractional partial differential equations using the homotopy analysis method. Numer. Meth. Part. Diff. Equ. 2010, 26, 448-479. [CrossRef]

28. Malvandi, A.; Hedayati, F.; Domairry, G. Stagnation point flow of a nanofluid toward an exponentially stretching sheet with nonuniform heat generation/absorption. J. Thermodyn. 2013, 2013, 764827. [CrossRef]

29. Abbasbandy, S.; Hayat, T.; Alsaedi, A.; Rashidi, M.M. Numerical and analytical solutions for Falkner-Skan flow of MHD Oldroyd-B fluid. Int. J. Numer. Methods Heat Fluid Flow 2014, 24, 390-401. [CrossRef]

30. Sheikholeslami, M.; Hatami, M.; Ganji, D.D. Micropolar fluid flow and heat transfer in a permeable channel using analytic method. J. Mol. Liq. 2014, 194, 30-36. [CrossRef]

31. Hayat, T.; Muhammad, T.; Alsaedi, A.; Alhuthali, M.S. Magnetohydrodynamic three-dimensional flow of viscoelastic nanofluid in the presence of nonlinear thermal radiation. J. Magn. Magn. Mater. 2015, 385, 222-229. [CrossRef]

32. Turkyilmazoglu, M. An effective approach for evaluation of the optimal convergence control parameter in the homotopy analysis method. Filomat 2016, 30, 1633-1650. [CrossRef]

33. Zeeshan, A.; Majeed, A.; Ellahi, R. Effect of magnetic dipole on viscous ferro-fluid past a stretching surface with thermal radiation. J. Mol. Liq. 2016, 215, 549-554. [CrossRef] 
34. Hayat, T.; Abbas, T.; Ayub, M.; Muhammad, T.; Alsaedi, A. On squeezed flow of Jeffrey nanofluid between two parallel disks. Appl. Sci. 2016, 6, 346. [CrossRef]

35. Muhammad, T.; Alsaedi, A.; Shehzad, S.A.; Hayat, T. A revised model for Darcy-Forchheimer flow of Maxwell nanofluid subject to convective boundary condition. Chin. J. Phys. 2017, 55, 963-976. [CrossRef]

(C) 2019 by the authors. Licensee MDPI, Basel, Switzerland. This article is an open access article distributed under the terms and conditions of the Creative Commons Attribution (CC BY) license (http://creativecommons.org/licenses/by/4.0/). 